\title{
THE INFLUENCE OF MECHANICAL STIMULUS ON NUTRIENT TRANSPORT AND CELL GROWTH IN ENGINEERED CARTILAGE: A FINITE ELEMENT APPROACH
}

\author{
S. Cortez ${ }^{1}$, A. Completo ${ }^{2}$, and J. L. Alves ${ }^{1}$ \\ ${ }^{1}$ Center for MicroElectroMechanical Systems (CMEMS) \\ University of Minho \\ Campus of Azurém 4800-058 Guimarães, Portugal \\ \{scortez, jlalves\}@dem.uminho.pt \\ ${ }^{2}$ Department of Mechanical Engineering \\ University of Aveiro \\ Campus Universitário de Santiago, 3810-193 Aveiro, Portugal \\ completo@ua.pt
}

Keywords: tissue engineering, cartilage, nutrient transport, cell growth, dynamic compression

\begin{abstract}
Osteoarthritis is a degenerative joint disease characterized by cartilage degeneration, which affects more people than any other joint disease. To overcome this problem, tissue engineering has been improving to restore tissue functionality developing new implantable cartilage. Bioreactors can provide an adequate nutrient transport to cells in the scaffold, a good mechanical stimuli and a hydrodynamic environment, which imposes a fluid flow to promote the cell proliferation. Finite element analysis of cartilage growth can be used to guide these tissue engineering experiments in order to produce cell scaffold constructs with specific biomechanical properties. In this work, a 3D finite element model was developed to simulate the diffusion and transport of nutrients and the cell growth kinetics in a porous scaffold when it is subject to different mechanical stimuli. The mass transport was defined by convection-diffusion equation, where the nutrient uptake was represented through the Michaelis-Menten kinetics and the fluid dynamics within the construct was modelled by Brinkman's equation. Cell growth kinetics was modelled by the Contois equation, which includes the effect of glucose concentration and the cell density saturation. The objective of this study was to understand the effect of mechanical loading in nutrition and cell growth during culture. Different mechanical stimuli $15 \%, 10 \%$ and $15 \%$ of compressive strain with frequencies of $0.5 \mathrm{~Hz}, 1 \mathrm{~Hz}$ and $2 \mathrm{~Hz}$ ) were performed during a period of 48 hours of cell culture. The spatial-temporal evolution of the local glucose, oxygen and lactate concentrations, the $\mathrm{pH}$ level and the cell density within the scaffold was analysed. The numerical simulations of solutes concentrations and cell growth show a good agreement with experimental results. These results show that fluid shear stress promoted by fluid dynamics inside the scaffold is influenced by compression and consequently the solute transport and the chondrocyte activity is affected for altered levels of stimulation.
\end{abstract}




\section{INTRODUCTION}

In tissue engineering, development of cartilage depends on the exchange of a suitable amount of nutrients, including oxygen and glucose, to cells during the culture process [1-3]. The chondrocytes during the culture process produces a large amount of lactate and its production rate is related to the glucose and oxygen metabolism [4]. The diffusion process and metabolism of cells develop concentration gradients of metabolites that affect the cell viability $[2,5-7]$.

The culture process under dynamic flow conditions has shown significant potential for the development of cartilage tissue [8]. In this culture process, cells are seeded into threedimensional scaffolds that are placed inside the bioreactor to provide nutrients and mechanical stimuli. When compared with the control constructs kept in a loading-free culture, the dynamic stimulation culture not only improves the mass exchange between cells and medium, but also exposes cells to physical stimulations [9]. The effects of dynamic compression may be due to fluid flow, tissue and cell deformation or hydrostatic pressurization. Compressioninduced fluid flow increases the shear stress, the rate of transport of nutrients and the biomass production inside the scaffold [10].

Applying dynamic compression loading at moderate levels as $2-15 \%$ strains $[8,11,12]$, 0.5-2.5 MPa stresses [13] and physiological frequencies between 0.001 to $1.0 \mathrm{~Hz}$ can stimulate the cell differentiation and the development of a functional tissue [9].

Despite the loading parameters to maximize the development of tissues in culture, other factors should be taken into account in tissue engineering, such as the type of the scaffold, the nutrient medium, and cellular factors, such as initial cell seeding density [14].

In this study, the effects of dynamic compression on metabolites transport and cellular biosynthesis in a chondrocyte-seeded agarose scaffold were investigated. This numerical model includes the consumption of glucose and oxygen, the production of lactate by cells, and the $\mathrm{pH}$ and shear stress effects on the cellular differentiation.

\section{METHODOLY}

\subsection{Nutrient transport formulation}

A mathematical formulation to describe the supply of metabolites to cells is presented. The time varying evolution of metabolites content in the three-dimensional scaffold is represented by diffusion-reaction and cell kinetics equations.

This numerical modelling assumes the diffusion of nutrients from a culture medium boundary condition and a consumption by cells within the scaffold matrix. The constitutive equations for each domain are follow detailed. Equations are written in the generic form for each metabolite $i$ (oxygen, glucose and lactate). The concentration in time for each specie is governed by the Fick's law of diffusion:

$$
\frac{\partial C^{i}}{\partial t}=\mathbf{D}^{i} \frac{\partial^{2} C^{i}}{\partial x^{2}}+\dot{q}
$$

and the oxygen and glucose uptake is assumed by Michaelis-Menten kinetics:

$$
\dot{q}^{i}=-\frac{V_{\max }^{i} C^{i}}{K_{m}^{i}+C^{i}} \rho_{\text {cell }}
$$


where $C^{i}$ is the concentration of the solute $i$ in the fluid phase, $\mathbf{D}^{i}$ the diffusion effective tensor, $V_{\max }^{i}$ the maximum uptake rate, $K_{m}^{i}$ the half-maximum rate concentration and $\rho_{\text {cell }}$ the cellular density.

Glucose and oxygen are consumed by cells, which synthesizes lactate into the scaffold. The content of lactate produced by chondrocytes is twice the number of moles of glucose consumption and a third of the number of moles of oxygen consumption [4] given by the following equation:

$$
\dot{q}^{l a c t}=-2 \dot{q}^{g l u}+\frac{1}{3} \dot{q}^{o x}
$$

The $\mathrm{pH}$ is linearly dependent on the concentration of lactate and its control can reduces the factor of two between the absorption of glucose and the lactate production. The $\mathrm{pH}$ less than 7 becomes a more acidic medium, causing an adverse effect on cell viability.

\subsection{Cell balance}

The cell kinetics includes cell migration, growth and death, and it is modelled by the Monod growth equation [15]. In this paper, the glucose concentration is used as the only limiting factor for cell growth, where a glucose concentration of $3.0 \times 10^{-10} \mathrm{~mol} / \mathrm{mm}^{3}$ is considered critical for chondrocyte viability [7].

To incorporate the influence of the shear stress acting on the chondrocytes, a modulation function $g(|\tau|)$ was assumed, as described by the following relation [16]:

$$
g(|\tau|)= \begin{cases}0.6+4|\tau| & |\tau| \in[0,0.1[\mathrm{~Pa} \\ 1 & |\tau| \in[0.1,0.6] \mathrm{Pa} \\ 2.5(1-|\tau|) & |\tau| \in] 0.6,1] \mathrm{Pa} \\ 0 & |\tau|>1 \mathrm{~Pa}\end{cases}
$$

where $|\tau|$ is the normalized fluid shear stress.

In this model, only the beneficial effect of shear stress on cell growth has been included. As the cell growth can influences the porosity due to increase of the solid volume fraction, the Mackie-Meares equation is used to include the porosity effect on the diffusion coefficients [15]. As consequence, the metabolites diffusion will be affected by the porosity of the scaffold. The decrease of the scaffold permeability with an increase of solid volume fraction was modelled by the Carman-Kozeny equation $[10,17]$ as:

$$
k=k_{0} \frac{n_{f}^{3}}{\left(1-n_{f}^{2}\right)}
$$

where $n_{f}$ is the fluid volume fraction and $k_{0}$ the initial permeability of the scaffold.

\section{FINITE ELEMENT IMPLEMENTATION}

The governing equations subject to initial boundary conditions were implemented using a computation tool (V-Biomech) [18] based on a finite element method (FEM) to solve the distribution of glucose, oxygen and lactate, and the cell differentiation in the scaffold in relation 
to time. A quarter of a 3D disc with $10 \mathrm{~mm}$ diameter and $3 \mathrm{~mm}$ height was meshed with 512 hexahedral finite elements. (Fig.1).

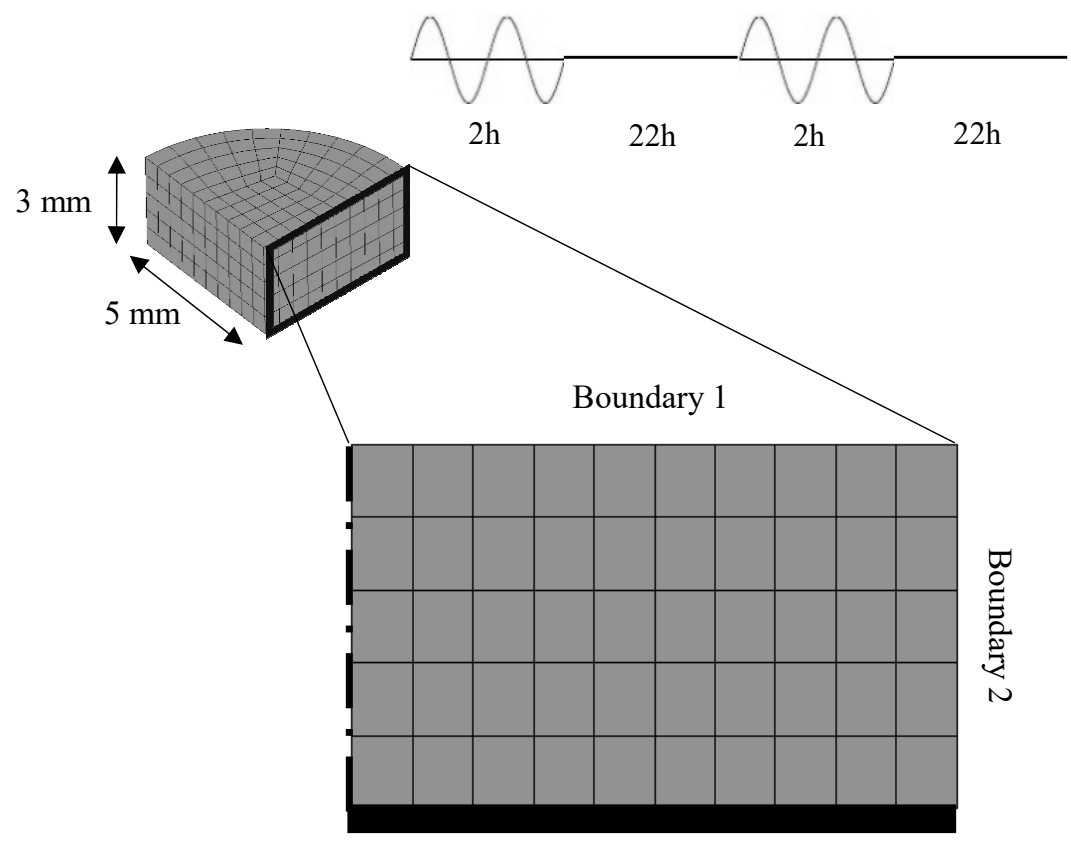

Figure 1: 3D mesh of the agarose disc submerged into a culture medium. Boundaries 1 and 2 are the surfaces in contact with the fluid. The cells are seeded into scaffold.

The model was based on a scaffold disc of $4 \% \mathrm{w} / \mathrm{w}$ agarose $\left(n_{f}=0.96\right.$ and $k_{0}=0.661 \mathrm{~mm}^{4}$ $\mathrm{N}^{-1} \mathrm{~s}^{-1}$ ) with a uniform cell seeding of 40000 cells $/ \mathrm{mm}^{3}$ and an initial oxygen, glucose and lactate concentration of $2.05 \times 10^{-10} \mathrm{~mol} / \mathrm{mm}^{3}, 5.10 \times 10^{-9} \mathrm{~mol} / \mathrm{mm}^{3}$ and $1.20 \times 10^{-9} \mathrm{~mol} / \mathrm{mm}^{3}$, respectively. The initial $\mathrm{pH}$ value of the scaffold was set at 7.4 and the diffusivity coefficients for each species are presented in Table 1.

The cell-seeded scaffold was considered to be submerged in a standard culturing environment of $5 \% \mathrm{CO}_{2}$ and $37^{\circ} \mathrm{C}$, with a boundary oxygen, glucose and lactate concentration of $2.05 \times 10^{-10} \mathrm{~mol} / \mathrm{mm}^{3}, 2.50 \times 10^{-8} \mathrm{~mol} / \mathrm{mm}^{3}$ and $2.30 \times 10^{-9} \mathrm{~mol} / \mathrm{mm}^{3}$, respectively. At the interface of the medium and the scaffold (boundaries 1 and 2), the concentrations are assumed to be continuous during the simulation and cells are not able to move out of the scaffold. Due to double symmetry about the centre line, only one quarter of the domain was computed.

\begin{tabular}{lllc}
\hline Parameters & Value & Units & Reference \\
\hline$D_{\text {medium }}^{\text {ox }}$ & $2.10 \times 10^{-3}$ & $\mathrm{~mm}^{2} / \mathrm{s}$ & {$[19]$} \\
$D_{\text {medium }}^{\text {glu }}$ & $1.00 \times 10^{-3}$ & $\mathrm{~mm}^{2} / \mathrm{s}$ & {$[20]$} \\
$D_{\text {medium }}^{\text {lact }}$ & $1.40 \times 10^{-3}$ & $\mathrm{~mm}^{2} / \mathrm{s}$ & {$[20]$} \\
$D_{\text {cell }}$ & $1.70 \times 10^{-8}$ & $\mathrm{~mm}^{2} / \mathrm{s}$ & {$[17]$} \\
$K_{m}^{o x}$ & $6.00 \times 10^{-12}$ & $\mathrm{~mol} / \mathrm{mm}^{3}$ & {$[4]$} \\
$K_{m}^{\text {glu }}$ & $3.50 \times 10^{-10}$ & $\mathrm{~mol} / \mathrm{mm}^{3}$ & {$[6]$} \\
$V_{\max }^{o x}$ & $1.18 \times 10^{-18}$ & $\mathrm{~mol} /(\mathrm{cell} \cdot \mathrm{s})$ & {$[4]$} \\
$V_{\max }^{\text {glu }}$ & $1.70 \times 10^{-17}$ & $\mathrm{~mol} /(\mathrm{cell} \cdot \mathrm{s})$ & {$[4]$} \\
\hline
\end{tabular}

Table 1: Diffusion parameters values used in the simulations. 
In this study, two simulations were performed: (i) free-swelling culture simulation and (ii) dynamic compressive loading simulation, with compressive strains of $5 \%, 10 \%$ and $15 \%$ for frequencies of $0.5 \mathrm{~Hz}, 1 \mathrm{~Hz}$ and $2 \mathrm{~Hz}$. Both simulations were tested during a period of 48 hours of cell culture. In the cyclic dynamic simulation, the displacement was applied on the top surface (boundary 1) of the construct during 2 hours and then a free-swelling was preserved during the next 22 hours. After this time, the stimulation was repeated during 2 hours and again, the free-swelling state was kept until reaches the 48 hours of the culture process. The average evolution within the scaffold of the local glucose, oxygen and lactate concentrations and the influence of the shear stress on cell kinetics was studied.

\section{RESULTS AND DISCUSSION}

A free-swelling (static) experiment and a dynamic compression with different combinations of strain $(5 \%, 10 \%$ and $15 \%)$ and frequency $(0.5 \mathrm{~Hz}, 1 \mathrm{~Hz}$ and $2 \mathrm{~Hz})$ were simulated for a time culture of 48 hours and the evolution in time of the average glucose, oxygen and lactate concentrations and the cell density within the scaffold was analysed.

\subsection{Influence on nutrient transport}

The average oxygen concentration versus time curves at frequencies of $0.5 \mathrm{~Hz}, 1.0 \mathrm{~Hz}$ and $2 \mathrm{~Hz}$ are illustrated in Figure $2 \mathrm{a}, \mathrm{b}$ and c, respectively. For each case, three different compressive strains, as $5 \%, 10 \%$ and $15 \%$ of the scaffold height were applied.

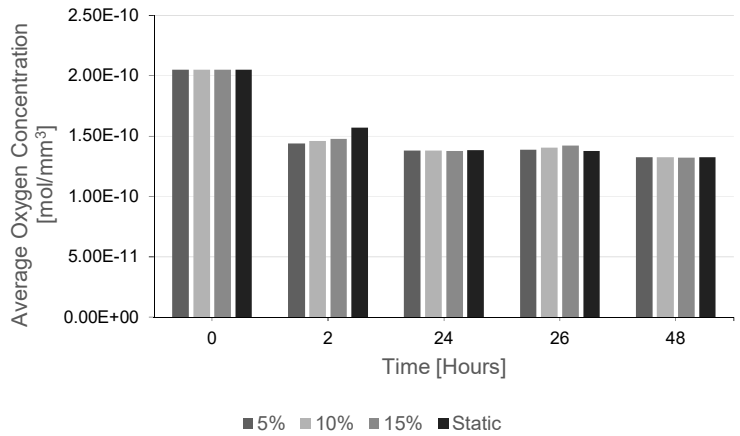

(a)

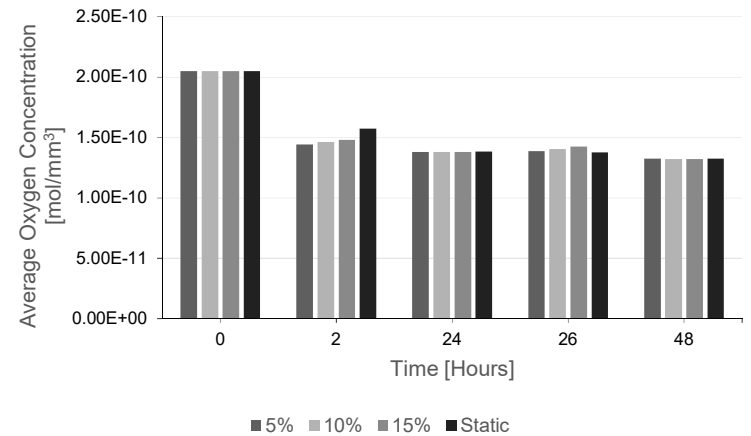

(b)

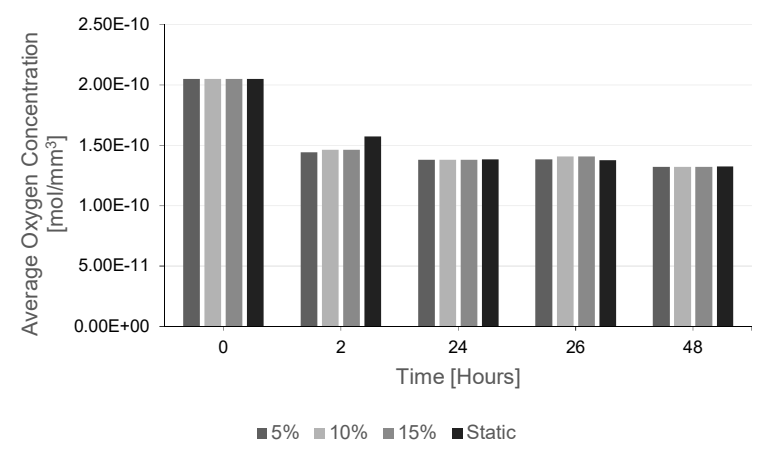

(c)

Figure 2: Average oxygen concentration for free-swelling conditions and for different dynamic compressive stimulations $(5 \%, 10 \%$ and 15\%) with frequencies of (a) $0.5 \mathrm{~Hz}$, (b) $1 \mathrm{~Hz}$ and (c) $2 \mathrm{~Hz}$.

All the three plots show a decrease on the average oxygen concentration inside the scaffold during the culture time, associated with the consumption of the oxygen inside the scaffold by chondrocytes. These results follow the expected trend showed in $[2,4,6]$. As in all simulations 
the medium is constantly updated, the oxygen diffuses into the scaffold and tends to reach a steady state. The minimum value of oxygen concentration was $1.32 \times 10^{-10} \mathrm{~mol} / \mathrm{mm}^{3}$. However, in cyclic compression stimulations the equilibrium of the oxygen concentration is reached faster (after 2 hours of incubation) than unloaded case, which can be associated with fluid velocities. After 24 hours of culture time, the chondrocytes consume oxygen at a slower rate. The $15 \%$ compression stimulations show to influence the oxygen concentrations due to the oxygen replacement rate induced by compression is larger than consumption rate by cells and consequently, the oxygen diffuses faster into the scaffold. At frequencies of $0.5 \mathrm{~Hz}$ and $1 \mathrm{~Hz}$ (Figure $2 \mathrm{a}$ and $\mathrm{b}$ ), the $15 \%$ compression stimulation showed to be slightly higher than the results for $2 \mathrm{~Hz}$ cyclic compression simulation. Low frequencies results in low velocities and consequently a higher fluid flow infiltration depth.

Figure 3 shows the evolution of the total glucose content in the scaffold during the cultivation time of 48 hours. The average glucose concentration under the $0.5 \mathrm{~Hz}, 1.0 \mathrm{~Hz}$ and $2 \mathrm{~Hz}$ frequency is illustrated in Figure 3a, b and c, respectively.

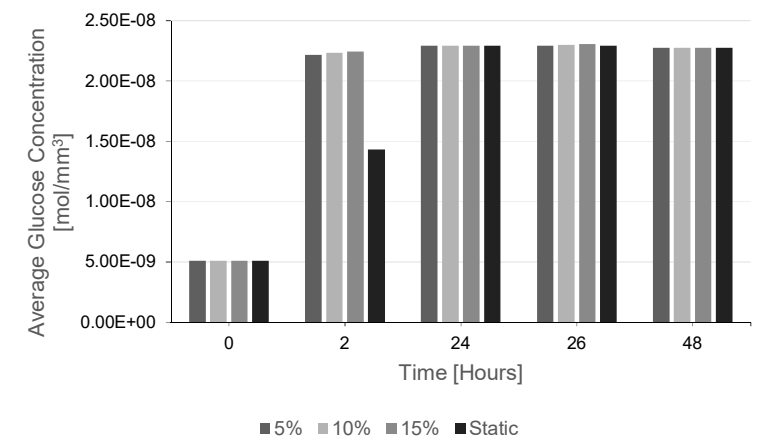

(a)

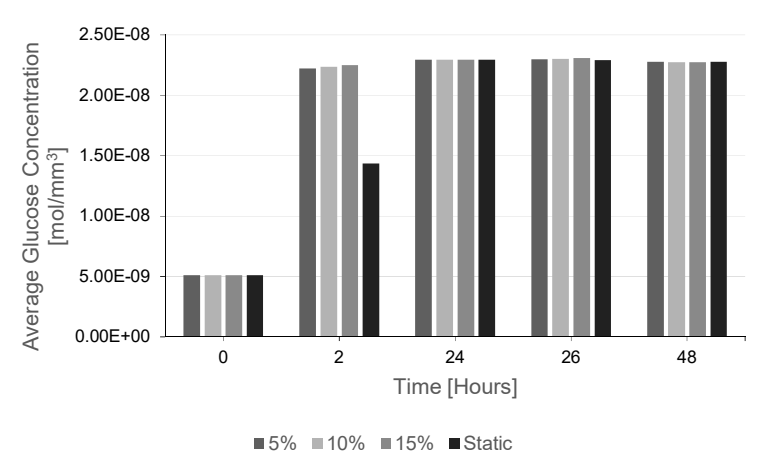

(b)

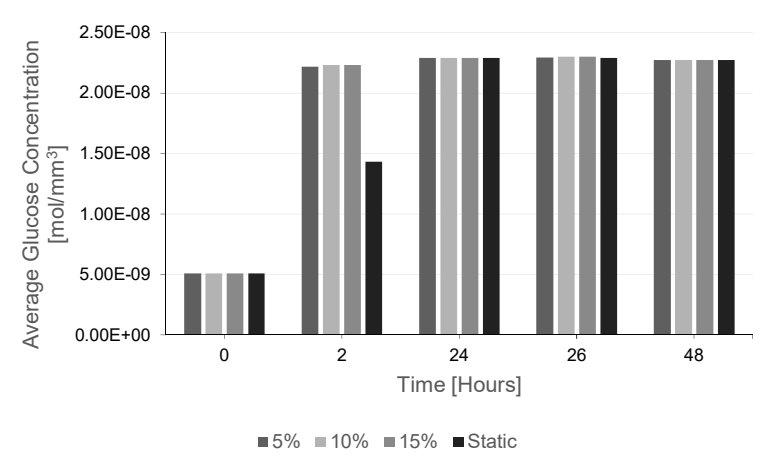

(c)

Figure 3: Average glucose concentration for free-swelling conditions and for different dynamic compressive stimulations $(5 \%, 10 \%$ and $15 \%$ ) with frequencies of (a) $0.5 \mathrm{~Hz}$, (b) $1 \mathrm{~Hz}$ and (c) $2 \mathrm{~Hz}$.

As the initial concentration inside the scaffold is lower than the medium, during the incubation time the glucose diffuses into the scaffold. As consequence, a softly increase trend of the average glucose concentration is observed for the unloaded simulation (free-swelling). Contrary to what occurs in oxygen plots, after 2 hours of cultivation the amount of glucose into the scaffold is higher in the stimulated case than for load-free simulation. Here, the steady state of glucose concentration is reached faster due to the fluid velocities imposed by compression. During the time, the glucose remained well above $1.0 \times 10^{-8} \mathrm{~mol} / \mathrm{mm}^{3}$ reaching a maximum value of $2.29 \times 10^{-8} \mathrm{~mol} / \mathrm{mm}^{3}$ at 26 hours. However, this value decreases slightly to 
$2.27 \times 10^{-8} \mathrm{~mol} / \mathrm{mm}^{3}$ at the end of the culture period due to the cell consumption. Even at high cell densities when the consumption is higher, glucose remains constant due medium update (e.g., at 48 hours). Despite 15\% compression stimulation showed to improve the glucose diffusion depth, the trend under different compressive stimulations remains identical. For this metabolite transport, frequency was not significant.

Figure $4 \mathrm{a}, \mathrm{b}$ and $\mathrm{c}$ shows the average lactate concentration produced inside the scaffold under the $0.5 \mathrm{~Hz}, 1.0 \mathrm{~Hz}$ and $2 \mathrm{~Hz}$ frequency, respectively. Lactate is produced by cells and then diffuses to the medium. Its content increases gradually during incubation time as computed using Equation 3. The obtained results agree well with experimental data showed in some studies $[2,4,6]$. For the first two hours, the lactate content much higher in cyclic compression simulations than free-swelling case. It is associated with the cell density and the glucose inside the scaffold, which is higher for compressive stimulation. When incubation time reaches 24 hours, lactate secretion slows down. As glucose in the culture environment is mostly consumed and reaches an equilibrium state (Figure 3), the rate of lactate production gradually decrease on time.

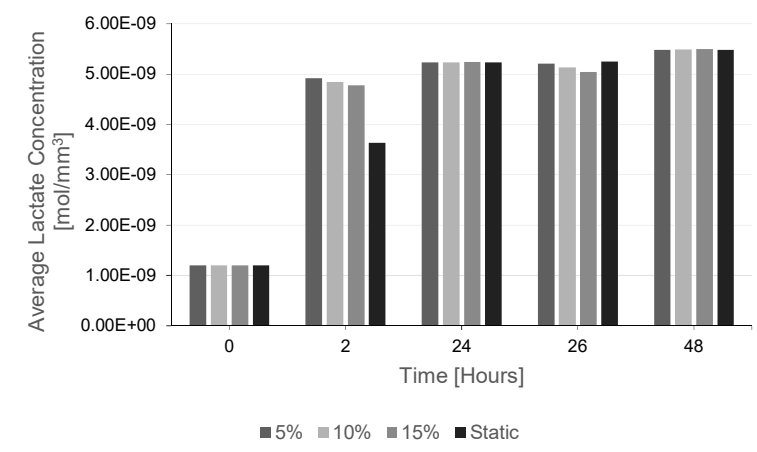

(a)

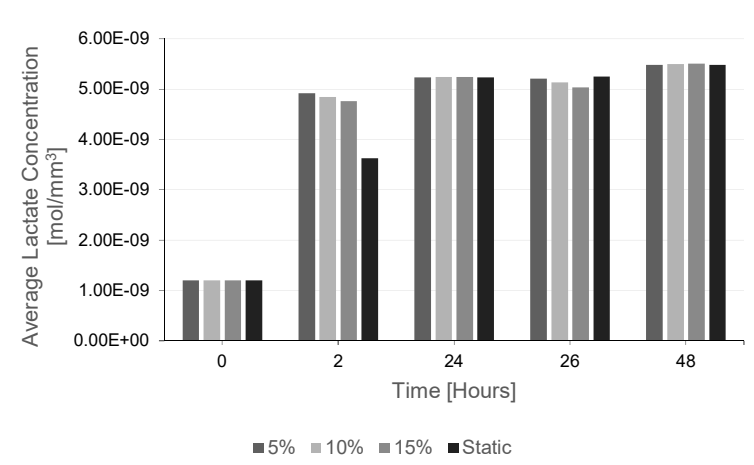

(b)

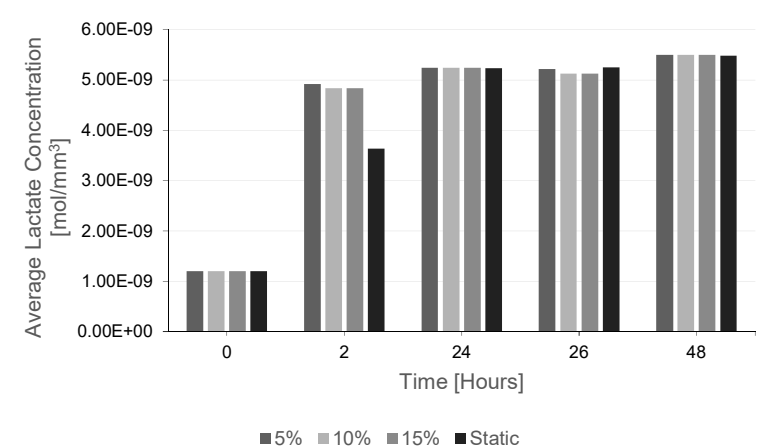

(c)

Figure 4: Average lactate concentration for free-swelling conditions and for different dynamic compressive stimulations (5\%,10\% and 15\%) with frequencies of (a) $0.5 \mathrm{~Hz}$, (b) $1 \mathrm{~Hz}$ and (c) $2 \mathrm{~Hz}$.

In cyclic compression simulations, when the compressive strain increases, the glucose content decreases. This phenomenon is associated with the increase of fluid velocities necessary to expel the lactate from the scaffold to the medium. The lactate removal is largest for $15 \%$ compression when the fluid velocity is higher. 


\subsection{Influence on cell proliferation}

Figure $5 \mathrm{a}, \mathrm{b}$ and $\mathrm{c}$ shows the average cell density inside the scaffold under the $0.5 \mathrm{~Hz}, 1.0$ $\mathrm{Hz}$ and $2 \mathrm{~Hz}$ frequency, respectively. In all stimulation regimes of 5\%,10\% and 15\% compression loading, there is a higher proliferation of cells $[2,4,6]$ comparing with the cell density obtained by free-swelling simulation. Observing Figure 2, the high cell growth complies with the low oxygen concentration.

When the scaffold is under compression, fluid culture medium is forced into the construct promoting the transport of nutrients to the cells but also generating a shear stress, which influence the cell kinetics. Compared to free-swelling culture outcome in Figure 4, more cells are resulted from dynamic loading cases, indicating the important roles of shear in promoting cell proliferation when nutrient supply is relatively constant.

The comparison between the simulations under the three different cyclic compressions shows that the fluid shear effect on cell growth is more significant at higher strains. For lower frequencies (Figure $4 \mathrm{a}$ and $\mathrm{b}$ ) the $15 \%$ compressive stimulation significantly enhanced the proliferation of cells. However, the maximum value of 47379 cell $/ \mathrm{mm}^{3}$ was reached by $1 \mathrm{~Hz}$ frequency simulation. For a high frequency of $2 \mathrm{~Hz}$ (Figure 5c) the average cell density was almost the same for all stimulations.

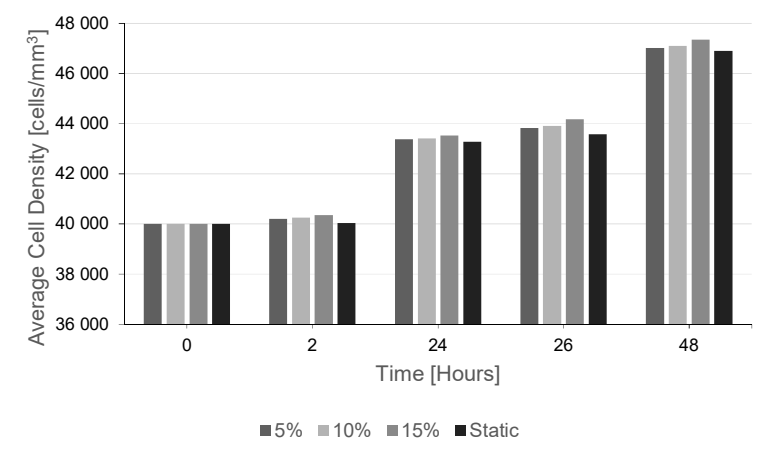

(a)

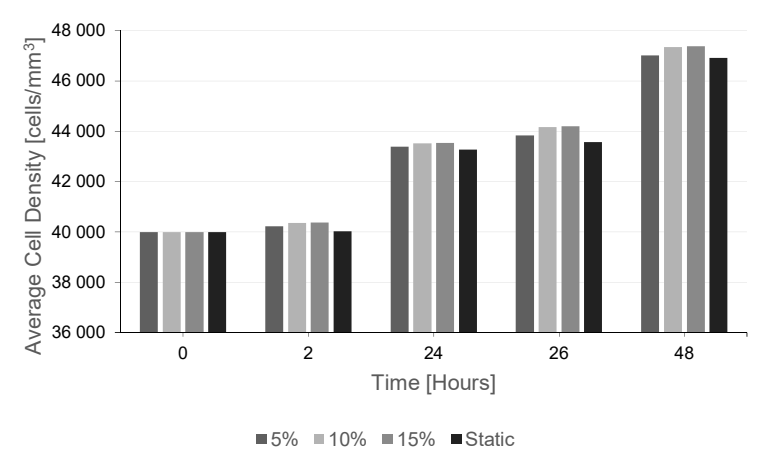

(b)

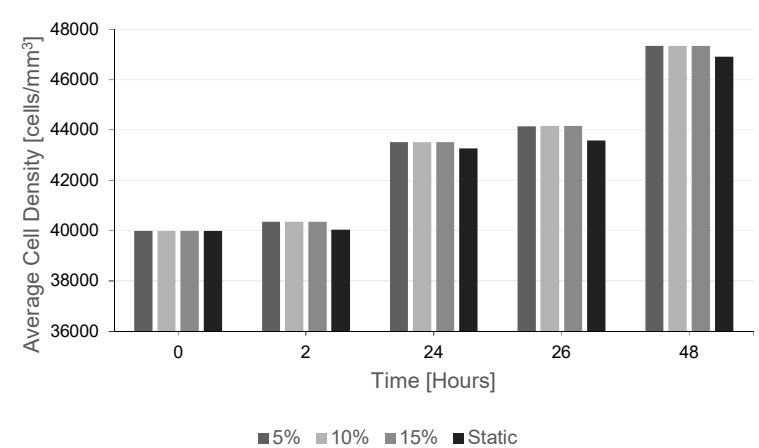

(c)

Figure 5: Average cell density for free-swelling conditions and for different dynamic compressive stimulations $(5 \%, 10 \%$ and 15\%) with frequencies of (a) $0.5 \mathrm{~Hz}$, (b) $1 \mathrm{~Hz}$ and (c) $2 \mathrm{~Hz}$.

Accompanying lactate accumulation in the scaffold, the culture environment becomes more acidic and the average $\mathrm{pH}$ decreases from 7.4. However, as the simulation time is too short (only 48 hours) a higher cell density was not achieved and the lactate production inside the scaffold was not sufficient to see the $\mathrm{pH}$ inhibition cell proliferation effects (when the $\mathrm{pH}$ is lower than 6.8). 


\section{CONCLUSIONS}

In summary, this work numerically analysed the effects of dynamic compression on nutrient transport and cellular proliferation in a chondrocyte-seeded agarose scaffold. The results show that fluid shear stress promoted by fluid velocities inside the scaffold is influenced by compression and consequently the solute transport and the chondrocyte activity is affected for altered levels of stimulation. In this study, the simulation of $15 \%$ compressive strain with 1 $\mathrm{Hz}$ compressive loading for 2 days seemed to be beneficial for chondrocytes proliferation.

The present numerical model is a helpful tool to clarify experimental studies of cell viability and transport of nutrients over the development of tissue-engineered constructs during bioreactor culture under nutrition and mechanical loading conditions.

\section{ACKNOWLEDGEMENTS}

Sara Cortez is grateful to FCT (Fundação para a Ciência e Tecnologia) for the PhD grant (SFRH/BD/87933/2012). This work is supported by FCT with the reference project UID/EEA/04436/2013, by FEDER funds through the COMPETE 2020 - Programa Operacional Competitividade e Internacionalização (POCI) with the reference project POCI-010145-FEDER-006941.

\section{REFERENCES}

[1] J. Malda, J. Rouwkema, D. E. Martens, E.P. le Comte, F.K. Kooy, J. Tramper, C.A. van Blitterswijk and J. Riesle, Oxygen gradients in tissue-engineered Pegt/Pbt cartilaginous constructs: Measurement and modelling, Biotechnology and bioengineering, 86(1), 9-18, 2004.

[2] S. Li, R.O. Oreffo, B.G. Sengers, and R.S. Tare, The effect of oxygen tension on human articular chondrocyte matrix synthesis: Integration of experimental and computational approaches. Biotechnology and bioengineering, 111(9), 1876-1885, 2014.

[3] B.G. Sengers, C.C. Van Donkelaar, C.W.J. Oomens, and F.P.T. Baaijens, Computational study of culture conditions and nutrient supply in cartilage tissue engineering. Biotechnology Progress, 21(4), 1252-1261, 2004.

[4] B.G. Sengers, H.K. Heywood, D.A. Lee, C.W. Oomens and D.L. Bader, Nutrient utilization by bovine articular chondrocytes: a combined experimental and theoretical approach. Journal of biomechanical engineering, 127(5), 758-766, 2005.

[5] C. Bandeiras, A. Completo, A. Ramos, A.T. Rufino, M. Ribeiro, J.P. Ferreira, and A.F. Mendes, Tissue Engineered Cartilage in Unconfined Compression: Biomechanical Analysis. Materials Today: Proceedings, 2(1), 355-364, 2015.

[6] T.H. Lin, H.Y. Jhang, F.C. Chu and C.A. Chung, Computational modeling of nutrient utilization in engineered cartilage. Biotechnology progress, 29(2), 452-462, 2013.

[7] S. Zhou, Z. Cui, and J.P. Urban, Nutrient gradients in engineered cartilage: metabolic kinetics measurement and mass transfer modeling.Biotechnology and bioengineering, 101(2), 408-421, 2008. 
[8] Y. H Tsuang, Y. S. Lin, L. T. Chen, C. K. Cheng, and J.S. Sun, Effect of dynamic compression on in vitro chondrocyte metabolism. The International journal of artificial organs, 31(5), 439-449, 2008.

[9] D. Liu, C.K. Chua, and K.F. Leong, A mathematical model for fluid shear-sensitive 3D tissue construct development. Biomechanics and modeling in mechanobiology, 12(1), 19-31, 2013.

[10] R. Sacco, P. Causin, P. Zunino, and M.T. Raimondi, A multiphysics/multiscale 2D numerical simulation of scaffold-based cartilage regeneration under interstitial perfusion in a bioreactor. Biomechanics and modeling in mechanobiology, 10(4), 577-589, 2011.

[11] R.L. Mauck, S.B. Nicoll, S.L. Seyhan, G.A. Ateshian and C.T. Hung, Synergistic action of growth factors and dynamic loading for articular cartilage tissue engineering. Tissue engineering, 9(4), 597-611, 2003.

[12] K.W. Ng, R.L. Mauck, L.Y. Statman, E.Y. Lin, G.A. Ateshian, and C.T. Hung, Dynamic deformational loading results in selective application of mechanical stimulation in a layered, tissue-engineered cartilage construct.Biorheology, 43(3, 4), 497-507, 2006.

[13] M.T. Raimondi, M. Moretti, M. Cioffi, C. Giordano, F. Boschetti, K. Laganà, and R. Pietrabissa, The effect of hydrodynamic shear on 3D engineered chondrocyte systems subject to direct perfusion. Biorheology, 43(3, 4), 215.-222, 2006.

[14] T. Mesallati, C.T. Buckley, T. Nagel, and D.J. Kelly, Scaffold architecture determines chondrocyte response to externally applied dynamic compression. Biomechanics and modeling in mechanobiology, 12(5), 889-899, 2013.

[15] C. Bandeiras, A. Completo, and A. Ramos, Influence of the scaffold geometry on the spatial and temporal evolution of the mechanical properties of tissue-engineered cartilage: insights from a mathematical model. Biomechanics and modeling in mechanobiology, 14(5), 1057-1070, 2015.

[16] M.M. Nava, M.T. Raimondi, and R. Pietrabissa, A multiphysics 3D model of tissue growth under interstitial perfusion in a tissue-engineering bioreactor. Biomechanics and modeling in mechanobiology, 12(6), 1169-1179, 2013.

[17] C.A. Chung, C.W. Chen, C.P. Chen, and C.S. Tseng, Enhancement of cell growth in tissue-engineering constructs under direct perfusion: Modeling and simulation. Biotechnology and bioengineering, 97(6), 1603-1616, 2007.

[18] J.L. Alves, N. Yamamura, T. Oda, C. Teodosiu, Numerical simulation of musculoskeletal systems by V-Biomech, Proceedings of $9^{\text {th }}$ International Symposium CMBBE2010, Valencia, Spain, 24-27 February, 43-48, 2010.

[19] M.T. Raimondi, E. Bonacina, G. Candiani, M. Laganà, E. Rolando, G. Talò, D. Pezzoli, R. D'Anchise, R. Pietrabissa and M. Moretti, Comparative chondrogenesis of human cells in a 3D integrated experimental-computational mechanobiology model.Biomechanics and modeling in mechanobiology, 10(2), 259-268, 2011.

[20] S. Hossain, D.J. Bergstrom, and X.B. Chen, A mathematical model and computational framework for three-dimensional chondrocyte cell growth in a porous tissue scaffold placed inside a bi-directional flow perfusion bioreactor.Biotechnology and bioengineering, 112(12), 2601-2610, 2015. 